\title{
Effects of Sagittal Spinopelvic Alignment on Motor Symptom and Respiratory Function in Mild to Moderate Parkinson's disease
}

\author{
DongYeon Kang ${ }^{1}$, SangMyung Cheon², MinJi Son ${ }^{3}$, HyeRyun Sung ${ }^{2}$, HyeYoung Lee ${ }^{4}$ \\ 'Department of Health Care and Science, College of Health Science, Dong-A University, Busan; ${ }^{2}$ Parkinson's Disease Center, Dong-A University \\ Hospital, Busan; ${ }^{3}$ Graduate School of Medical, Dong-A University, Busan; ${ }^{4}$ Department of Physical Therapy, Keimyung University Dongsan Medical \\ Center, Daegu, Korea
}

Purpose: This study examined the effects of sagittal spinopelvic alignment on the clinical parameters, motor symptoms, and respiratory function in patients with mild to moderate Parkinson's disease (PD).

Methods: This study was a prospective assessment of treated patients ( $n=28$, Hoehn and Yahr [H\&Y] stage 2-3) in a PD center. Twentyeight subjects (68.5 \pm 5.7 years) participated in this study. The clinical and demographic parameters, including age, sex, symptoms duration, treatment duration, and H\&Y stage, were collected. Kinematic analysis was conducted in the upright standing posture with a motion capture system. A pulmonary function test (PFT) was performed in the sitting position using a spirometer. The motor symptoms were assessed on part III of the movement disorder society sponsored version of the unified Parkinson's disease rating scale (MDS-UPDRS). SPSS 18.0 was used to analyze the collected data.

Results: The exceeding 12 degrees group of the lower trunk showed significantly higher on the clinical parameters than the below 12 degrees group. In addition, the exceeding 12 degrees group of the lower trunk showed a significantly lower forced expiratory volume at one second $\left(\mathrm{FEV}_{1}\right)$ / forced vital capacity (FVC) (\%) and 25-75\% forced mid-expiratory flow (FEF) (L/sec) than in the below group. On the other hand, there was no difference in the upper trunk and the cervical pelvis between the groups.

Conclusion: These findings suggest that the sagittal balance in the lower trunk is related to the clinical parameters and respiratory function, but not the motor symptoms in patients with mild to moderate PD.

Keywords: Parkinson's disease, Spinopelvic alignment, Respiratory function

\section{서 론}

파킨슨병(Parkinson's disease, $\mathrm{PD}$ )의 대표적인 임상증상은 경직(rigidity), 안정시 진전(tremor of rest), 운동느림(brady-kinesia) 그리고 자세불 안정(postural instability)과 같은 운동장애로 소개되고 있지만-4 다양 한 비운동장애뿐만 아니라 병의 진행과 함께 환자의 약 $1 / 3$ 이상에서 는 머리, 목, 몸통 그리고 다리 관절이 앞으로 굽은 자세변형(stooped or bent posture)이 나타난다. ${ }^{5.7}$ 그뿐만 아니라 약 2-12\% 정도에서는 피 사증후군(pisasyndrome), 몸통굽힘증(camptocormia, bent syndrome) 및 머리가 앞으로 숙여지는(antecollis) 등의 심한 변형까지도 나타난 다. ${ }^{5-8}$

이러한 것의 원인은 움직임을 조절하는 기저핵, 시상핵 및 소뇌의 손상 또는 앞이마엽 기능이상(frontal lobe dysfunction)과 관련이 있는

Received Mar 25, 2019 Revised Apr 29, 2019

Accepted Apr 29, 2019

Corresponding author DongYeon Kang

E-mail dongyeon68@naver.com
것으로 제시되고 있지만,10 현재까지 병리학적 기전이 명확하게 밝혀 진 것은 아니며 이에 대한 약리반응 또한 연구마다 다양하게 나타나 고 있다.5,11 그뿐만 아니라 파킨슨병 환자의 경우에는 외과적 척추교 정술로 인한 합병증 발생이 높은 것으로 알려져 있다.

일반적으로 지나치게 앞으로 굽은 자세는 환자의 몸통움직임을 제한하고 허리통증, 균형 및 보행장애를 초래해 일상생활은 물론 사 회생활에까지 부정적인 영향을 미치며 넘어짐(falls)의 원인이 되기도 한다. ${ }^{89}$ 하지만 파킨슨병 환자의 경우에 몸통이 앞으로 구부러지는 자세는 운동느림, 불안정한 자세와 같은 운동장애에 대한 보상작용 (compensation)으로 보행동결(freezing of gait, $\mathrm{FOG}$ )이 나타나는 환자 의 보행개시에 도움이 될 수 있는 것으로 제시되고 있어 ${ }^{12}$ 이들의 자 세와 임상증상에 대한 올바른 이해를 돕기 위해 다양한 연구가 필요 한부분이다. 
자세변형은 파킨슨병 환자에서도 시상면(sagittal plane)과 관상면 (coronal plane)에서 복합적으로 나타난다. ${ }^{6}$ 하지만 척추질환관련 치료 에서 시상면의 균형원리를 먼저 이해하는 것이 우선이다. ${ }^{13}$ 따라서 파 킨슨병 환자의 적절한 치료 및 관리를 위해 시상면 자세변형에 대한 이해가 필수적이다.

현재까지 파킨슨병 환자의 자세와 관련된 연구는 시상면 자세변형 과 임상 지표와의 관련성, $7,12,13$ 자세평가방법 ${ }^{7,9}$ 자세 관련된 주요 지표 13,14 및 중재방법 ${ }^{15}$ 등에 대해 진행되었다. 이 중 시상면 자세변형과 임 상 지표와 관련성에 관한 결과를 구체적으로 살펴보면 앞으로 굽은 자세를 가진 파킨슨병 환자 190명(m: 122, f: 68)의 나이, Hoehn and Yahr H\&Y (stage), 질병기간, 허리통증 및 골다공증(osteoporosis) 정도 가 10-17개월 전후 자세변화에 유의한 영향을 미치는 것을 확인하였 다 $(\mathrm{p}<0.05)^{7}$ 또한 Hoehn and Yahr H\&Y stage 1-3인 환자 $(\mathrm{n}=175)$ 를 대 상으로 시상면 자세균형과 임상지표의 관련성을 분석한 결과 척추엉 치 각도(spinosacral angle)는 진단기간, 나이, H\&Y, UPDRS-motors와 유의한 음의 상관관계를, 척추골반 각도(spinopelvic angle)는 H\&Y (stage)와 유의한 양의 상관관계가 있음을 실제로 확인하였다 $(\mathrm{p}<0.05){ }^{13}$ 하지만 이러한 연구는 대상자의 자세변형의 진행정도에 관계없이 진행되어 몸통굽힘증을 보이는 환자와 그렇지 않은 환자의 특성 차이를 이해하는 데에는 부족한 부분이 존재한다.

자세변형 유발인자에는 근병증, 골격계 및 연부조직 변화뿐만 아 니라 근긴장이상, 경직, 고유감각 및 감각운동이상 등이 제안되는데 ${ }^{14}$ 자세불안정, 근경직, 근긴장이상, 근병증과 고유감각 손상 등을 겪는 파킨슨병 환자에게 척추변형이 동반되어 나타날 경우에는 환자에게 미치는 임상적 영향은 더 심각할 수 있다.13

한편 선행연구에서 후만증(kyphosis)이 있는 여성을 대상으로 들숨 량과 허파활량을 검사한 결과 등뼈의 후만각도가 클수록 호흡기능 이 감소되어 있는 것과 ${ }^{16}$ 전방머리자세(forward head posture)를 가진 대상자들은 그렇지 않은 사람들보다 Forced vital capacity, FVC과 forced expiratory volume at one second, $\mathrm{FEV}_{1}$ 정도가 낮다1는 것을 확인 하였다. 그뿐만 아니라 전방머리자세는 가로막 수축과 가슴 및 배의 움직임 감소와 가슴우리의 상승을 유도한다고 ${ }^{18}$ 하여 비정상적인 시 상면의 자세는 호흡기능에 부정적인 영향을 미치는 것을 제시하였다.

파킨슨병 환자의 경우에도 몸통의 굽은 각도가 클수록 허파활량 (vital capacity, VC)을 제한하고 이것이 호흡곤란(breathlessness)까지 유도한다면 이들의 독립적인 일상생활의 범위는 더 협소해질 수밖에 없다.6,10

일반적으로 건강한 사람은 자세에 따른 호흡능력의 차이가 있다. 그러나 한 연구에서 몸통굽힘증이 있는 파킨슨병 환자는 누운자세 와 앉은자세에서 노력성 페활량(Forced vital capacity, FVC)과 1초간 노력성 호기량(forced expiratory volume at one second, $\mathrm{FEV}_{\mathrm{l}}$ ) 등에서 차
이를 보이지 않았다는 결과 $(\mathrm{p}<0.05)^{19}$ 에서 이들의 자세변형과 호흡기 능의 관련성은 일반적인 대상자와 같지 않다는 것을 예측할 수 있다. 특히, 파킨슨병 환자의 호흡기능장애가 병의 초기부터 시작된다는 점을 ${ }^{20}$ 생각한다면 이들의 자세변형과 호흡기능의 관련성을 구명하 는 것은 임상에서 이들의 근골격 및 신경계뿐만 아니라 호흡재활치 료의 전략수립측면에서도 연구의 필요성이 제시된다.

따라서 이 연구는 임상적으로 파킨슨병 환자의 자세변형에 대한 유용한 정보와 자세변형 조기관리 프로그램 및 개선중재 프로그램 의 기초자료를 제공하는 데에 목적을 두고 몸통굽힘증이 없는 H\&Y stage 2-3인 파킨슨병 환자의 시상면 척추골반정렬을 등허리, 허리골 반 및 목골반으로 분류하여 선 자세에서 각 부위의 기울기와 임상특 성, 주요 운동증상 및 호흡기능과의 상호관련성을 분석하고 이러한 요소에 영향을 미치는주요 부위와 그 정도를 구명하고자 한다.

\section{연구 방법}

\section{1. 연구대상}

$\mathrm{D}$ 의료원 파킨슨병센터에 내원하는 60 세 이상 환자 중 UK Parkinson's disease society brain bank 임상기준에 근거하여 파킨슨병(PD) H\&Y

Table 1. The characteristics of subjects

\begin{tabular}{|c|c|}
\hline Variable & Subjects $(n=28)$ \\
\hline Age (yr) & $68.45 \pm 5.77$ \\
\hline Height (cm) & $158.97 \pm 9.43$ \\
\hline Weight (kg) & $59.81 \pm 7.93$ \\
\hline Upper trunk $\left({ }^{\circ}\right)$ & $6.27 \pm 6.64$ \\
\hline Lower trunk $\left(^{\circ}\right)$ & $12.16 \pm 5.86$ \\
\hline Cervical-pelvis $\left({ }^{\circ}\right)$ & $7.58 \pm 3.85$ \\
\hline Duration of treatment (yr) & $5.91 \pm 6.08$ \\
\hline Duration of symptom (yr) & $6.82 \pm 5.06$ \\
\hline Levodopa equivalent dose (mg) & $577.08 \pm 353.62$ \\
\hline H\&Y (stage) & $2.39 \pm 0.45$ \\
\hline Freezing of gait (score) & $0.58 \pm 0.93$ \\
\hline Rigidity (score) & $6.41 \pm 3.83$ \\
\hline Posture (score) & $0.98 \pm 0.21$ \\
\hline Gait (score) & $0.96 \pm 0.47$ \\
\hline Total motor (score) & $32.58 \pm 9.68$ \\
\hline Total UPDRS (score) & $46.3 \pm 14.5$ \\
\hline VC (L/s) & $2.33 \pm 0.99$ \\
\hline $\mathrm{FVC} \mathrm{(L/S)}$ & $7.99 \pm 30.18$ \\
\hline $\mathrm{FEV}_{1}(\mathrm{~L} / \mathrm{s})$ & $2.12 \pm 0.55$ \\
\hline $\mathrm{FEV}_{1} / \mathrm{FVC}(\%)$ & $91.72 \pm 5.87$ \\
\hline 25-75\% FEF (L/s) & $3.05 \pm 0.92$ \\
\hline $\mathrm{PCF}(\mathrm{L} / \mathrm{S})$ & $413.07 \pm 82.39$ \\
\hline
\end{tabular}

Values are presented as mean \pm standard deviation, Mean \pm SD. H\&Y: Hoehn and Yahr, UPDRS: unified Parkinson's disease rating scale. 
stage 2-3으로 판정된 28명(남: 17, 여: 11)이다. 이들은 자립보행으로 일 상생활이 가능하고 인지장애(K-MMSE $\geq 24$ 점)가 없으며 최근 1 년 이 내 급·만성 호흡 기질환 및 심혈관질환을 진단받지 않았고 근골격계 질환이나 척추관련 질환으로 외과적 수술을 받지 않았다. 그리고 Movement disorder society unified parkinson's disease rating scale (MDS-UPDRS) part III의 자세항목에서 2 (score) 이하에 해당되고 시 상면의 목골반 기울기가 $15^{\circ}$ 이하인 자 ${ }^{6}$ 들이다. 그리고 모두 연구의 목적을 이해하고 동의하였다.

이 연구에서는 표본집단의 평균값과 빈도분석에 의해 산출된 중 앙값을 기준으로 하여 허리골반의 시상면 기울기가 $12^{\circ}$ 이하 집단 $(\mathrm{n}=14)$ 과 $12^{\circ}$ 초과 집단 $(\mathrm{n}=14)$ 으로 분류하였다. 이들의 일반적인 신 체적 특성은 다음과 같다(Table 1).

\section{2. 실험방법}

1) 측정도구

(1) MDS-UPDRS

이 연구에서는 I. 정신, 행동 및 정서, II. 일상생활활동, III. 운동기능검 사, IV. 약물치료에서 나타나는 부작용(이상운동 유무), V. modified H\&Y, VI. 일상생활평가척도(modified schwab and england activities of daily living, SEADL)로 구성된 MDS-UPDRS ${ }^{21}$ 를 사용하였고 신경과 전문의에 의해 평가되었다. 6 개 항목 중 장애정도를 나타내는 $\mathrm{V}$. modified H\&Y stage III, 운동기능검사의 총점과 세부항목 중 보행동 결, 경직, 자세, 보행 점수를 사용하였다. 모든 항목의 점수가 높을수 록 증상이 심한 것을 나타낸다.

(2) 폐기능검사 (pulmonary function test, PFT)

PFT는 선행연구1를 참고하였다. PFT 측정은 spirometer (SP 205 spirometer, Schiller, USA)를 이용하여 폐활량 $(\mathrm{VC})(\mathrm{L} / \mathrm{s})$, 노력성 폐활량 $(\mathrm{FVC})(\mathrm{L} / \mathrm{s}), 1$ 초간 노력성 호기량 $\left(\mathrm{FEV}_{\mathrm{l}}\right)(\mathrm{L} / \mathrm{s})$, 최고 호기유량(peak cough flow, PCF)(L/s) 그리고 25-75\% 강제 호기유량(25-75\% forced mid-expiratory flow, $25-75 \% \mathrm{FEF})(\mathrm{L} / \mathrm{sec})$ 을 측정하였다. 의자에서 10 분 동안 안 정을 취한 상태에서 실시하였고 검사자는 환자에게 측정에 대한 자 세한 설명을 하여 측정의 신뢰성을 높일 수 있도록 하였다. 측정치는 미국 흉부학회의 가이드라인에 따라 3 회 이상 반복 측정한 후 가장 큰 값을 사용하였다.

\section{(3) 시상면 척추정렬평가}

이 연구의 시상면의 척추정렬은 6대의 적외선 카메라로 구성된 $3 \mathrm{D}$ motion capture system (Vicon, MX-T10, Oxford Metrics, Oxford, UK)을 이용하여 분석하였다.

영상자료 수집 및 분석은 Nexus software (Vicon, Oxford, UK)를 이
용하였고 영상자료의 샘플링 주파수는 $100 \mathrm{~Hz}$ 로 하였으며 수집된 자 료는 Butterworth low-pass filter 2차, 차단주파수 $6 \mathrm{~Hz}$ 로 필터링하였 다. ${ }^{22}$ 모든 대상자들은 실험을 위해 12 시간 동안 약물복용을 금지하 였고 밀착된 상하의 복장을 착용하였다. 모든 절차는 선행연구 ${ }^{23}$ 를 참고하였다.

신체 모델은 Vicon plug-in-gait model에 기반하였고 $14 \mathrm{~mm}$ 반사마커 를 부착하고 해부학적 자세로 서서 정면의 표식을 주시하였다. 자료는 시작음이 울리고 5초 동안 수집하였다. 각 부위의 중앙점은 목(cervical point)은 쇄골과 C7 마커를 이은 선의 중간, 등허리(thoracic point)은 흥 골과 Th10 마커를 이은 선의 중간 그리고 골반(pelvic point)은 좌우 ASIS 마커와 PSIS 마커의 중간지점으로 하였다. 또한 기저면은 좌우측 발가락과 뒤꿈치 마커의 중간지점으로 하였고 질량중심점은 Vicon plug-in-gait model의 중심점을 신체에 적용하여 산출하였다.

이 연구에서는 이것을 토대로 하여 등허리(upper trunk)의 내측각 도는 목과 몸통의 중앙점을 이어서, 허리골반(lower trunk)은 몸통과 골반의 중앙점을 이어서 벡터와 벡터의 내적을 산출하였다. 또한 목 골반(cervical-pelvis)기울기는 몸통이 광역좌표계의 수직축에서 전방 으로 기운 정도를 산출하였고 전방으로 기울 때 값을 양(+), 후방으로 기울 때 값을 음(-)으로 나타낸다 (Figure 1).

\section{3. 자료처리}

모든 자료처리는 SPSS 18.0 Ver.을 이용하여 각 항목의 평균(M)과 표

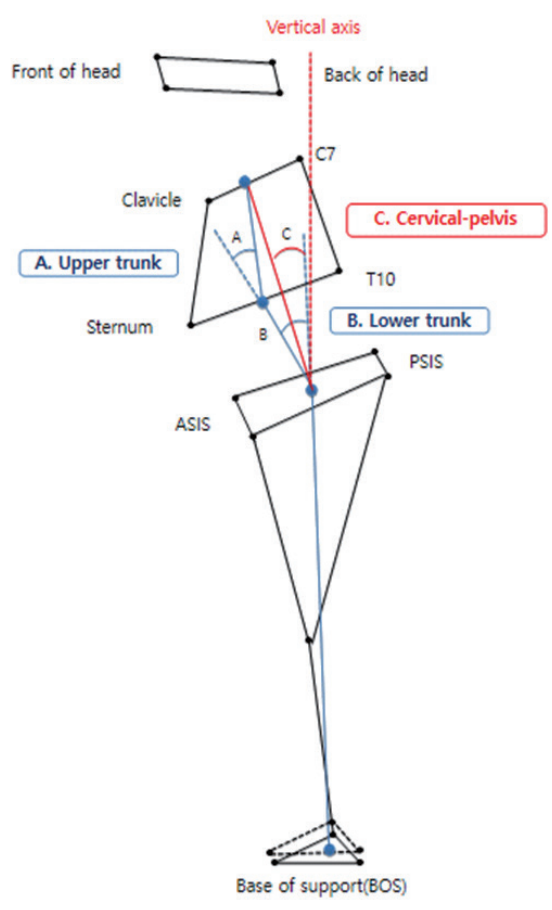

Figure 1. Definitions of points and angles used for postural measurements in patients with Parkinson's disease. 
준편차(SD)를 구하였고 항목 간 상호관련성 검증을 위해 상관분석 을 실시하여 Pearson's correlation coefficient를 산출하였고 허리골반 기울기가 $12^{\circ}$ 이하 집단과 $12^{\circ}$ 초과 집단의 각 항목을 비교하기 위하 여 Independent t-test를 실시하였다. 모든 통계적 유의수준은 $\mathrm{p}<0.05$ 로 설정하였다.

\section{결 과}

$\mathrm{H} \& Y$ stage 2-3인 파킨슨병 환자(PD)(n=28)의 시상면 척추정렬, 운동 증상 및 호흡기능의 관련성을 분석한 결과는 다음과 같다(Table 2). 허리골반(lower trunk)의 시상면 기울기는 이들의 치료기간(r=0.45),

Table 2. Pearson's correlation coefficients among motor symptom and respiratory function related to sagittal alignment in subjects

\begin{tabular}{|c|c|c|c|}
\hline Variable & Upper trunk $\left(6.27^{\circ} \pm 6.64^{\circ}\right)$ & Lower trunk $\left(12.16^{\circ} \pm 5.86^{\circ}\right)$ & Cervical-pelvis $\left(7.58^{\circ} \pm 3.85^{\circ}\right)$ \\
\hline Age (yr) & 0.36 & 0.32 & 0.02 \\
\hline Duration of treatment (yr) & 0.27 & $0.45^{*}$ & -0.01 \\
\hline Duration of symptom (yr) & 0.34 & 0.35 & -0.03 \\
\hline Levodopa equivalent dose (mg) & 0.08 & 0.23 & -0.14 \\
\hline $\mathrm{H} \& Y$ (stage) & 0.29 & 0.35 & 0.15 \\
\hline Freezing of gait (score) & 0.04 & $0.39^{\star}$ & -0.30 \\
\hline Rigidity (score) & 0.18 & -0.09 & 0.17 \\
\hline Posture (score) & -0.23 & $0.35^{*}$ & -0.15 \\
\hline Gait (score) & 0.25 & -0.06 & 0.15 \\
\hline Total motor (score) & 0.33 & -0.02 & 0.30 \\
\hline Total UPDRS (score) & 0.19 & 0.35 & 0.06 \\
\hline Upper trunk (score) & 1.00 & -0.06 & $0.50^{*}$ \\
\hline Lower trunk $\left({ }^{\circ}\right)$ & -0.06 & 1.00 & -0.17 \\
\hline Cervical-pelvis $\left(^{\circ}\right)$ & $0.50^{*}$ & -0.17 & 1.00 \\
\hline VC $(L / S)$ & 0.02 & -0.16 & -0.02 \\
\hline FVC (L/S) & 0.22 & -0.23 & -0.88 \\
\hline $\mathrm{FEV}_{1}(\mathrm{~L} / \mathrm{s})$ & -0.03 & -0.29 & -0.20 \\
\hline $\mathrm{FEV}_{1} / \mathrm{FVC}(\mathrm{L} / \mathrm{s})$ & 0.00 & -0.15 & -0.43 \\
\hline $25-75 \%$ FEF (L/s) & 0.00 & -0.32 & -0.12 \\
\hline $\mathrm{PCF}(\mathrm{L} / \mathrm{s})$ & -0.16 & -0.28 & -0.14 \\
\hline
\end{tabular}

Mean \pm SD

H\&Y: Hoehn and Yahr, UPDRS: unified parkinson's disease rating scale. ${ }^{*} p<0.05$.

Table 3. Comparisons of motor symptom and respiratory function related to degrees of the lower trunk in subjects

\begin{tabular}{|c|c|c|c|}
\hline variable & $\begin{array}{l}\text { Below } 12 \text { degrees group } \\
\quad(n=14, m: 9, f: 5)\end{array}$ & $\begin{array}{l}\text { Excess } 12 \text { degrees group } \\
\qquad(n=14, m: 8, f: 6)\end{array}$ & p-value \\
\hline Lower trunk angle $\left(^{\circ}\right)$ & $7.81 \pm 3.63$ & $16.52 \pm 4.18$ & $<0.001$ \\
\hline Age (yr) & $66.27 \pm 4.96$ & $70.64 \pm 5.85$ & 0.043 \\
\hline Duration of treatment (yr) & $2.70 \pm 2.86$ & $7.37 \pm 5.43$ & 0.013 \\
\hline Duration of symptom (yr) & $4.872 \pm 4.32$ & $8.69 \pm 5.28$ & 0.049 \\
\hline Levodopa equivalent dose (mg) & $467.03 \pm 303.32$ & $687.14 \pm 376.34$ & 0.100 \\
\hline H\&Y (stage) & $2.21 \pm 0.37$ & $2.57 \pm 0.47$ & 0.037 \\
\hline Freezing of gait (score) & $0.28 \pm 0.46$ & $0.89 \pm 1.17$ & 0.085 \\
\hline Rigidity (score) & $6.92 \pm 3.79$ & $5.89 \pm 3.95$ & 0.486 \\
\hline Posture (score) & $0.92 \pm 0.26$ & $1.03 \pm 0.13$ & 0.191 \\
\hline Gait (score) & $1.00 \pm 0.33$ & $0.92 \pm 0.58$ & 0.696 \\
\hline total motor (score) & $33.35 \pm 8.56$ & $31.82 \pm 10.96$ & 0.683 \\
\hline total UPDRS (score) & $46.67 \pm 13.09$ & $45.92 \pm 16.28$ & 0.894 \\
\hline Upper trunk angle $\left(^{\circ}\right)$ & $5.31 \pm 7.37$ & $7.37 \pm 4.36$ & 0.455 \\
\hline Cervical-pelvis angle $\left({ }^{\circ}\right)$ & $7.86 \pm 3.42$ & $7.30 \pm 4.36$ & 0.707 \\
\hline$V C(L / S)$ & $2.56 \pm 0.59$ & $2.11 \pm 1.00$ & 0.235 \\
\hline FVC (L/s) & $2.34 \pm 0.59$ & $2.22 \pm 0.64$ & 0.627 \\
\hline $\mathrm{FEV}_{1}(\mathrm{~L} / \mathrm{s})$ & $2.23 \pm 0.54$ & $1.99 \pm 0.57$ & 0.299 \\
\hline $\mathrm{FEV}_{1} / \mathrm{FVC}(\%)$ & $94.46 \pm 3.59$ & $88.75 \pm 6.52$ & 0.012 \\
\hline $25-75 \% \mathrm{FEF}(\mathrm{L} / \mathrm{s})$ & $3.48 \pm 0.85$ & $2.63 \pm 0.80$ & 0.012 \\
\hline $\mathrm{PCF}(\mathrm{L} / \mathrm{s})$ & $439.58 \pm 13.09$ & $390.35 \pm 84.63$ & 0.131 \\
\hline
\end{tabular}

Mean $\pm S D$

H\&Y: Hoehn and Yahr, UPDRS: unified parkinson's disease rating scale. 
보행동결 $(\mathrm{r}=0.39)$ 및 자세 $(\mathrm{r}=0.35)$ 와 유의한 양의 상관을 보였다 $(\mathrm{p}<0.05)$. 그러나 등허리(upper trunk)과 목골반(cervical-pelvis)의 시상 면 기울기는 운동증상과 호흡기능의 모든 항목과 유의한 상관이 없 었다 $(\mathrm{p}<0.05)$.

임상증상과 양의 상관을 보인 허리골반의 시상면 기울기를 $12^{\circ}$ 초 과 집단과 $12^{\circ}$ 이하 집단으로 분류하여 운동증상과 호흡기능을 비교 한 결과는 $12^{\circ}$ 초과 집단이 $12^{\circ}$ 이하 집단보다 나이(years), 치료기간 (years), 증상기간(years) 및 $\mathrm{H} \& \mathrm{Y}$ (stage)가 유의하게 높았다 $(\mathrm{p}<0.05)$. 그 리고 $12^{\circ}$ 이하 집단은 $12^{\circ}$ 초과 집단보다 $\mathrm{FEV}_{1} / \mathrm{FVC}(\%)$ 와 $25-75 \% \mathrm{FEF}$ $(\mathrm{L} / \mathrm{s})$ 에서 유의하게 높게 나타났다 $(\mathrm{p}<0.05)($ Table 3$)$.

\section{고 찰}

파킨슨병 환자의 임상진료에서 시상면 자세변형이 중요한 이유는 임 상지표와의 관련성뿐만 아니라 척추골반과 시상면 균형이 자세조절 과 하지의 보상메커니즘에도 영향을 미치는 이유 때문이다.13,14 이들 의 자세변형에 대한 발생메커니즘에 대해서는 현재까지 명확히 알려 져 있지는 않다. 그러나 자세안정이 척추주변의 굽힘근과 폄근의 적 절한 동시수축에 의해 이루어진다는 측면에서 설명한다면 환자의 자 세가 앞으로 굽어지는 것은 바닥핵의 과잉반응에 의한 몸통 굽힘근 의 기능항진 때문이며 또한 운동장애에 대한 보상반응의 하나로 이 해될 수 있다:

이 연구에서 파킨슨병 H\&Y (stage) 2-3의 28명(68.45 years)을 대상으 로 시상면 척추골반정렬을 등허리, 허리골반 및 목골반으로 분류하 여 임상특성, 주요 운동증상 및 호흡기능과 관련성을 분석하였다. 그 리고 그 결과에서 상호관련성을 보인 허리골반기울기를 $12^{\circ}$ 이하 집 단 $\left(\mathrm{n}=14,7.810 \pm 3.63^{\circ}\right)$ 과 $12^{\circ}$ 초과 집단 $\left(\mathrm{n}=14,16.520 \pm 4.18^{\circ}\right)$ 으로 분류 하여 각 항목을 비교하였다. 이러한 분류기준은 파킨슨병 환자를 대 상으로 이 연구에서 동작분석기를 통해 측정하여 산출한 방법과 유 사한 선행연구를 참고할 수 없어 표본집단의 평균값과 빈도분석에 의해 산출된 중앙값을 기준으로 임의로 정하였다.

선행연구6,8에서는 파킨슨병이 진행되면서 나타나는 앞으로 굽은 자세의 기준을 약 $25^{\circ}$ 를 초과하지 않는 것으로 제시하고 있지만 몸통 굽힘증은 약 $15^{\circ}-45^{\circ}$ 의 불수의적인 등허리 굽힘으로 정의하고 있다. ${ }^{20}$ 현재까지 파킨슨병 환자의 자세와 임상특성, 주요 운동증상과 관련 된 대부분의 선행연구는 이러한 환자의 구분없이 다양한 측정도구 (X-ray ${ }^{10,13}$, SpinalMouse, ${ }^{7}$ 줄자 ${ }^{12}$ )를 사용하여 진행되었다. 그러나 이 연 구에서는 몸통굽힘증이 나타나지 않은 파킨슨병 환자의 자연스러운 일상생활에서 서 있는 자세에 대한 자료를 수집하기 위해 동작분석 기(motion analysis)를 사용하였다. 그러므로 선행연구 결과와 구체적 으로 비교 및 논의하는 데에 많은 제한점이 있다.
이 연구에서는 허리골반기울기가 치료기간 $(\mathrm{r}=0.45)$, 보행동결 $(r=0.39)$ 및 자세 $(r=0.35)$ 와 양의 관련성을 보였다. 따라서 이러한 주 요결과에 대해 선행연구를 참고하여 다음과 같이 논의하였다.

먼저 대상자의 치료기간은 상관분석뿐만 아니라 허리골반기울기 가 $12^{\circ}$ 초과한 집단 $(\mathrm{n}=14)$ 과 $12^{\circ}$ 이하인 집단 $(\mathrm{n}=14)$ 의 비교분석에서 도 큰 허리골반기울기가 상대적으로 작은 것보다 치료기간이 긴 것으 로 나타났다. 이러한 결과는 몸통 전체기울기와 치료기간의 양의 관 련성을 보인 연구를기람고할 때 비정상적인 자세변화가 시작되면서 나타나는 초중기 파킨슨병 환자의 자세특성으로 생각된다. 이러한 것 은 이 연구의 대상자들의 치료기간과 다음에서 제시할 자세에 대한 허리골반기울기의 관련성을 종합적으로 생각해 보면 더욱 그렇다.

이 연구의 대상자는 몸통굽힘증을 동반하지 않은 병의 초중기에 해당하는 경증 자세장애 대상자로서 이들의 치료기간이 길어질수 록 허리골반이 앞으로 기울어진다는 것을 생각해보면 초중기 파킨 슨병 환자의 자세변형은 허리골반부에서 시작된다는 가능성을 제시 할 수 있다. 자세변화와 비정상적인 근긴장은 요추 디스크 및 연부조 직과 요추의 골격구조에 스트레스를 증가시킬 수 있다. 따라서 몸통 굽힘증이나 피사증후군과 같은 몸통의 근긴장이상은 파킨슨병 환자 의 척추 위치이상의 원인이 될 수 있으며 24,25 그리고 기본적으로 시상 면 척추정렬의 주요 요소는 골반이다.13 이러한 측면에서 본다면 파킨 슨병 환자의 자세변화와 허리기울기의 관련성은 충분히 제시될 수 있고 이 연구의 결과는 몸통굽힘증을 동반하지 않은 초중기 환자 자 세변형의 특성으로 생각될 수 있다.

그리고 이 연구에서 이 연구의 대상자의 허리골반기울기가 클수록 FOG정도가 심하다는 결과에 대한 설명은 선행연구에서는 환자가 스스로 자세교정이 가능한 단계라면 이들의 앞으로 굽은 자세는 $\mathrm{FOG}$ 를 겪는 환자의 보행 개시에 도움이 된다고 하였다. 그 이유는 자 세가 앞으로 굽어지면서 질량중심(center of mass, $\mathrm{COM}$ )이 앞으로 이 동하게 되어 보행을 시작하기 위한 자세조절이 용이하기 때문이 다.12,26,27 이러한 관점에서 본다면 허리골반기울기만으로 복잡한 발생 메커니즘에서 비롯되는 FOG를 설명할 수는 없지만, 이 연구의 결과 에 대한 설명이 가능하다. 대상자 $(\mathrm{n}=28)$ 의 허리골반기울기는 MDSUPDRS의 III. 운동기능검사 중 자세 $(\mathrm{score})(\mathrm{r}=0.35)$ 와 유의한 관련성 을, 환자의 자세를 측정하여 얻은 실측치에서는 목골반기울기와 등 허리기울기가 유의한 상관 $(\mathrm{r}=0.50)$ 을 보였다(Table 2). 이러한 결과는 환자의 운동기능과 관련된 자세평가와 정적인 자세만의 평가 결과의 차이점에서 비롯된 것으로 생각된다.

이들의 자세평가는 파킨슨병 환자의 치료반응을 평가하기 위한 임상척도로 사용되는 MDS-UPDRS의 III. 운동기능검사에 포함된 자세 항목의 점수를 적용하였다. 이 항목은 0-4척도로 이 연구의 대 상자는 0-2 (score)에 해당되며 0 (score)은 정상, 2 (score)는 검사자 요구 
에 따라 자세를 수정할 수 있는 경증정도의 자세장애를 나타낸다. 따 라서 대상자의 자세는 전문의 소견상 정상에서 경증정도의 자세장 애에 해당한다. 그리고 실제 자세평가는 위에서 제시하였듯이 동작 분석기(motion analysis)를 사용하였다. 따라서 이러한 평가방법 차이 에 따른 결과라고 생각한다. 하지만 목골반기울기와 등허리기울기가 유의한 상관 $(\mathrm{r}=0.50)$ 을 보인 것에 대해서는 분명한 설명이 어렵다. $\mathrm{H} \& \mathrm{Y}$ (stage) $1-3$ 인 환자 $(\mathrm{n}=175)$ 의 척추엉치각도(spinosacral angle, SSA) 는 L1-S1의 기울기와 상관 $(\mathrm{r}=0.78, \mathrm{p}<0.05)$ 이 있는 것 ${ }^{13}$ 으로 나타났다 는 것을 볼 때 더욱 그렇다.

한편 이 연구에서 허리골반기울기가 $12^{\circ}$ 초과한 집단 $(\mathrm{n}=14)$ 은 $12^{\circ}$ 이하인 집단 $(\mathrm{n}=14)$ 보다 나이(years), 치료기간(years), 증상발현기간 (years), $\mathrm{H} \& \mathrm{Y}$ (stage)에서 유의하게 높았고 $\mathrm{FEV}_{\mathrm{l}} / \mathrm{FVC}$ (\%) 및 25-75\% FEF $(\mathrm{L} / \mathrm{s})$ 에서는 유의하게 낮은 것으로 나타났다 $(\mathrm{p}<0.05)$ (Table 3). 이러한 결과는 다른 연구8,13,15에서도 자세변화에 따른 나이, 치료기간 및 증 상발현기간, $\mathrm{H \& Y}$ (stage)의 상관에 대한 결과와 유사한 맥락이다. 그 리고 10-17개월 동안 파킨슨병 환자 190명(m: 122, f: 68)의 자세변화를 나이, H\&Y (stage) 및 기간, 허리통증과의 관련성 $(\mathrm{p}<0.05)$ 을 구명한 연 구에서도 참고할 수 있다.

또한 파킨슨병 환자의 자세와 호흡기능에 관한 연구19를 살펴보면 60세 이상의 몸통굽힘증을 동반한 파킨슨병(H\&Y stage 1-5) 환자 11 명과 동일 연령대의 건강한 10 명의 호흡기능을 바로누운자세와 $45^{\circ}$ 앞으로 굽힌 자세에 따라 비교하였다. 그 결과 파킨슨병 환자의 자세 에 따른 $\mathrm{FEV}_{1} / \mathrm{FVC}(\mathrm{L})$ 에는 변화가 없었다( $\left.\mathrm{p}<0.05\right)$. 하지만 이 연구에 서는 허리골반기울기에 따른 $\mathrm{FEV}_{1} / \mathrm{FVC}(\%)$ 및 $25-75 \% \mathrm{FEF}(\mathrm{L} / \mathrm{s})$ 의 차 이를 확인하였다. 일반적으로 몸통구힘증과 같은 앞으로 숙이는 자 세는 가슴확장을 제한하여 폐기능을 저하시키는 원인이 된다고 하 였다.

이 연구에서 28명의 몸통굽힘증이 없는 파킨슨병(H\&Y stage 2-3) 환자의 시상면 자세와 임상특성, 주요 운동장애 및 호흡기능의 관련 성에 대해 분석하여 첫째, 몸통굽힘증이 없는 파킨슨병 초중기 환자 의 시상면 균형에서 의미 있는 것은 허리골반기울기이며 이것이 증가 할수록 MDS-UPDRS의 III. 운동기능검사 항목 중 자세 및 보행동결 장애정도가 심하다. 둘째, 이 연구에서 허리골반기울기가 큰 사람은 기울기가 상대적으로 작은 사람보다 나이가 많고 증상발현 및 치료 기간이 길었고 호흡기능이 저하되어 있다는 결론을 얻었다.

이 연구의 흥미로운 점은 몸통굽힘증이 없는 파킨슨병 초중기 환 자의 허리골반기울기의 중요성을 새롭게 제시함으로써 초중기 파킨 슨병 환자의 자세변형에 대한 유용한 정보를 제공하였다는 것이다. 그러나 이 연구에는 대상자수가 적고 X-ray 촬영 등을 통해 산출된 임상적 파라미터를 구체적으로 분석하지 않았고 파킨슨병 환자에서 발생률이 비교적 높은 만성 요통과의 관련성을 제시하지 못해 이 연
구의 결과를 다른 연구결과와 충분히 비교 및 분석하여 이해하지 못 하는 아쉬움이 존재한다. 따라서 초중기 파킨슨병 환자의 자세균형 에서 허리골반기울기의 의미를 재확인하고 이들의 자세변형에 대한 조기관리 프로그램 및 개선중재 프로그램의 신뢰도 높은 기초자료 를 제공하기 위해서 임상 파라미터사용과 효과크기(effect size) 등을 고려한 향후 연구가 계획되어야 할 것으로 생각된다.

\section{REFERENCES}

1. Kang DY, Cheon SM, Lee KS et al, Correlations amang respiratoty function, UPDRS and senior fitness in Parkinson's disease patients. J Kor Phys Ther. 2014;26(2):48-55.

2. Bang DH, Noh HJ. Effects of aerobic exercise on disease severity and walking ability in patients with Parkinson's disease. J Kor Phys Ther. 2016;28(4):227-31.

3. Song HS, Kim JY. Clinical feasibility of mental practice for gait ability improvement of Parkinson disease patients: ABA single subject design. J Kor Phys Ther. 2014;26(6):398-402.

4. Lee DK, Kim EK, Kim YN et al. Effects of a virtual reality training program on balance and lower muscular strength of Parkinson's disease patients. J Kor Phys Ther. 2013;25(2):96-102.

5. Capecci M, Serpicelli C, Fiorentini L et al. Postural rehabilitation and Kinesio taping for axial postural disorders in Parkinson's disease. Arch Phys Med Rehabil. 2014;95(6):1067-75.

6. Doherty KM, van de Warrenburg BP, Peralta MC et al. Postural deformitiesin Parkinson's disease. Lancet Neurol. 2011;10(6):538-49.

7. Khlebtovsky A, Djaldetti R, Rodity et al. Progression of postural changes in Parkinson's disease: quantitative assessment. J Neurol. 2017;264(4): 675-83.

8. Benninger F, Khlebtovsky A, Roditi Y et al. Beneficial effect of levodopa therapy on stooped posture in Parkinson's disease. Gait Posture. 2015; 42(3):263-8.

9. Nair P, Bohannon RW, Devaney L et al. Reliability and validity of nonradiologic measures of forward flexed posture in Parkinson disease. Arch Phys Med Rehabil. 2017;98(3):508-16.

10. Bissolotti L, Gobbo M, Villafañe JH et al. Spinopelvic balance: new biomechanical insights with clinical implications for Parkinson's disease. Eur Spine J. 2014;23(3):576-83.

11. WilczyNski J, Pedrycz A, Mucha D et al. Body posture, postural stability, and metabolic age in patients with Parkinson's disease. Biomed Res Int. 2017;2017:1-9.

12. Mikami K, Shiraishi M, Kawasaki T et al. Forward flexion of trunkin Parkinson's disease patients is affected by subjective vertical position. PLoS One. 2017;12(7):1-9.

13. Bissolotti L, Berjano P, Zuccher P et al. Sagittal balance is correlated with Parkinson's disease clinical parameters: an overview of spinopelvic alignment on 175 consecutive cases. Eur Spine J. 2017;26(4):471-8.

14. Forsyth AL, Paul SS, Allen NE et al. Flexed truncal posturein Parkinson disease: measurement reliability and relationship with physical and cognitive impairments, mobility, and balance. J Neurol Phys Ther. 2017; 41(2):107-13 
15. Capecci M, Serpicelli C, Fiorentini L et al. Postural rehabilitation and kinesio taping for axial postural disorders in Parkinson's disease. Arch Phys Med Rehabil. 2014;95(6):1067-75.

16. Lorbergs AL, O'Connor GT, Zhou Y et al. Severity of kyphosisand declinein lung function: the framingham study. J Gerontol A Biol Sci Med Sci. 2017;72(5):689-94.

17. Kang JI, Jeong DK, Choi H. Correlation between pulmonary functions and respiratory muscle activity in patients with forward head posture. J Phys Ther Sci. 2018;30(1):132-5.

18. Kim MS, Cha YJ, Choi JD. Correlation between forward head posture, respiratory functions, and respiratory accessory muscles in young adults. J Back Musculoskelet Rehabil. 2017;30(4):711-5.

19. Marinelli P, Colosimo C, Ferrazza AM et al. Effect of camptocormia on lung volumes in Parkinson's disease. Respir Physiol Neurobiol. 2013; 187(2):164-6.

20. Monteiro L, Souza-Machado A, Valderramas S et al. The effect of levodopa on pulmonary function in Parkinson's disease: a systematic review and meta-analysis. Clin Ther. 2012;34(5):1049-55.

21. Goetz CG, Tilley BC, Shaftman SR et al. Movement disorder-society- sponsored revision of the unified Parkinson's disease rating scale (MDSUPDRS): scale presentation and clinimetric testing results. Movement Disorders. 2008;23(15):2120-70

22. Akram S, Frank JS, Jog M. Parkinson's disease and segmental coordination during turning: I. Standing turns. Can J Neurol Sci. 2013;40(4):5129.

23. Kim Y, Cheon SM, Youm C et al. Depression and posture in patients with Parkinson's disease. Gait Posture. 2018;61:81-5.

24. Margraf NG, Wrede A, Deuschl G et al. Pathophysiological concepts and treatment of camptocormia. J Parkinsons Dis. 2016;166(3):485-501.

25. Galazky I, Caspari C, Heinze HJ et al. The prevalenceof chroniclow back painand lumbar deformitiesin patients with Parkinson's disease: implications on spinal surgery. Eur Spine J. 2018;27(11):2847-53.

26. Boonstra TA, van Vugt JP, van der Kooij et al. Balance asymmetry in Parkinson's disease and its contribution to freezing of gait. PLoS One. 2014;9(7):1-12.

27. Khallaf ME, Fayed EE. Early postural changes in individuals with idiopathic Parkinson's disease. Parkinsons Dis. 2015;2015:1-6. 